\title{
Petrol Tüketiminin Durağanlık Özelliklerinin Araştırılması: OECD Ülkeleri için Ampirik Bir Analiz
}

\author{
Investigating the Stationarity Properties of Oil Consumption: an Empirical \\ Analysis for OECD Countries
}

\section{Fatma KIZILKAYA' ${ }^{1}$ ]}

\section{öz}

Değişen ve gelişen dünyada üretim faaliyetleri enerji kaynaklarına bağımlıdır. Dünyada enerji ihtiyacının önemli bir bölümü fosil yakıtlardan elde edilmektedir. Ulaşım, inşaat, sanayi, konut ve elektrik üretimi gibi çeşitli ekonomik faaliyetlerde sıklıkla kullanılan petrol, doğal gaz ve kömür ile beraber üç ana fosil yakıt türünden biridir. Geniş kullanım alanı olan petrolün rezervlerinin sınırlı olması önemli bir sorundur. Enerji tüketimi ile makroekonomik değişkenler arasındaki yakın ilişki nedeniyle, enerji tüketiminin durağanlık özelliğinin araştırılması politika yapıcılar için oldukça önemlidir. Enerji tüketimi serisinin durağan olması durumunda, enerji tüketimine gelen bir şok geçici olacaktır. Ancak enerji tüketimi durağan değilse, şokların etkisi kalıcı olacaktır. Bu çalışmada OECD ülkeleri için petrol tüketiminin durağanlık özelliği gösterip göstermediği araştırılmaktadır. Analizlerde 1965-2019 dönemleri ele alınmış ve hem keskin hem de yumuşak ve pürüzsüz kırılmaları göz önünde bulunduran panel durağanlık testi kullanılmıştır. Çalışmada kullanılan panel durağanlık testinde keskin kırılmalar, kırılma tarihlerinin içsel olarak belirlendiği kukla değişkenler ile dikkate alınırken, yumuşak kırılmalar ise Fourier yaklaşımı ile dikkate alınmıştır. Elde edilen bulgular panelin geneli için petrol tüketimi serisinin durağan olduğunu ortaya koymaktadır. Petrol tüketimi serisi birim kök içermediğinden petrol tüketimine yönelik şokların geçici olduğu ve zamanla eski haline geri döneceği anlaşılmaktadır. Bireysel durağanlık testi sonuçlarına göre 23 ülke için petrol tüketimi serisi durağan olarak elde edilmiştir. Bu sonuçlara göre, OECD ülkelerinde sürdürülebilir kalkınma hedefleri için uygulanacak politikaların her ülke üzerinde farklı etkileri olabileceğini söylemek mümkündür.

Anahtar Kelimeler: Petrol tüketimi, Panel durağanlık testi, Fourier, Enerji, OECD ülkeleri

Jel Sınıflaması: C23, C50, Q43
'Dr. Öğr. Üyesi, Malatya Turgut Özal Üniversitesi, Sağlık Bilimleri Fakültesi, Malatya-Türkiye

ORCID: F.K. 0000-0002-1028-9341

\section{Sorumlu yazar/Corresponding author:} Fatma KIZILKAYA,

Malatya Turgut Özal Üniversitesi, Sağlık Bilimleri Fakültesi, Malatya-Türkiye

\section{E-posta/E-mail:}

fatma.kizilkaya@ozal.edu.tr

Başvuru/Submitted: 01.12.2021 Revizyon Talebi/Revision Requested: 24.12.2021

Son Revizyon/Last Revision Received: 27.12.2021

Kabul/Accepted: 29.12 .2021

Atıf/Citation: Kizilkaya, F. (2022). Petrol tüketiminin durağanlık özelliklerinin araştırılması: OECD ülkeleri için ampirik bir analiz. Iktisat Politikası Araştırmaları Dergisi Journal of Economic Policy Researches, 9(1), 121-137.

https://doi.org/10.26650/JEPR1030877 


\begin{abstract}
In a changing and developing world, production activities are dependent on energy resources. A significant part of the energy needed in the world is obtained from fossil fuels. Petroleum is one of the three main types of fossil fuels, along with natural gas and coal, widely used in various economic activities such as transportation, construction, industry, housing, and electricity generation. The limited reserves of petroleum, which have a wide usage area, is a significant problem. Due to the close relationship between energy consumption and macroeconomic variables, policymakers must investigate the stationarity properties of energy consumption. If energy consumption is stationary, a shock to energy consumption will be temporary. However, if the energy consumption is not stationary, the effect of the shocks will be permanent. This study investigates whether oil consumption is stationary for OECD countries. The analyses are carried out using a panel stationarity test with sharp and smooth breaks for 1965-2019. In this test procedure, dummy variables, in which the break dates are determined endogenously, are used for sharp breaks, while the Fourier approach captures smooth breaks. The findings reveal that the oil consumption series is stationary for the panel. Since the oil consumption series does not include a unit root, it is understood that the shocks to oil consumption are temporary and will return to their previous state in time. According to the individual stationarity test results, the oil consumption series for 23 countries is obtained as stationary. According to these results, it is possible to say that the policies to be implemented for sustainable development goals in OECD countries may have different effects on each country.
\end{abstract}

Keywords: Oil consumption, Panel stationarity test, Fourier, Energy, OECD countries

Jel Classification: C23, C50, Q43

\title{
EXTENDED ABSTRACT
}

In a changing and developing world, production activities are dependent on energy resources. A significant part of the energy needed in the world is obtained from fossil fuels. One of these fossil fuels, Petroleum, is the primary production input for countries. It is used in almost all automotive, defense, and textile sectors. Therefore, the limited petroleum reserves, which have a wide usage area, are significant. In addition, since the spread of oil resources varies from region to region, some countries are source countries for oil, and some are dependent on oil. The economic importance of oil in all these countries is indisputable.

The Covid-19 pandemic, which emerged in 2019, has affected many sectors. One of these sectors is the energy sector. Global energy demand is estimated to have dropped by $4.5 \%$ in 2020 due to the pandemic. The worldwide decline in oil consumption accounts for about three-quarters of the total decline in energy demand. Considering this change in oil consumption, it is crucial to investigate whether the impact of shocks to oil consumption is temporary or permanent. If the oil consumption series is found to be stationary, it means that the shocks to oil consumption are temporary and will return to their previous state in the short term. If the oil consumption series is not stationary, shocks to oil consumption are permanent. Whether the energy consumption is stationary is also necessary to estimate the energy consumption. If the shocks to energy consumption are permanent, it can be expected that critical macroeconomic variables will take over this persistence, given the importance of energy for other sectors in the economy. By transferring this structure of the non-stationary 
oil consumption variable to other variables, the stationarity properties of many macroeconomic variables can change. However, if the energy consumption series is not stationary, past behavior will not matter in predicting future demand. In other words, it will not be possible to predict the future oil demand with a non-stationary oil consumption series. In this case, it is necessary to consider other variables that explain energy consumption to create future energy demand forecasts.

Unit root tests can examine the impact of shocks on oil consumption. The Fourier approach is used in this study. The Fourier approach can be used to capture unknown structural breaks or neglected nonlinearity in the deterministic component of the model. In addition, the use of the Fourier approach transforms the problem of choosing the appropriate functional form into choosing the most appropriate number of frequencies to include in the approach. In this direction, it is investigated whether the oil consumption series is stationary for OECD countries. The data for the period 1965-2019 and the Fourier stationarity test developed by Li, Ranjbar, and Chang (2015), which considers the cross-section dependency, are used in the analyses. The results obtained for the panel show that the oil consumption series is stationary. According to the results of the individual stationarity test, the oil consumption series for 23 countries (Canada, USA, Colombia, Austria, Belgium, Czechia, Denmark, Finland, France, Germany, Greece, Hungary, Ireland, Italy, Luxembourg, Netherlands, Norway, Portugal, Slovakia, Spain, Sweden, Switzerland, United Kingdom) is obtained as stationary. In addition, the oil consumption series has a unit root for 10 OECD countries (Mexico, Chile, Iceland, Poland, Turkey, Israel, Australia, Japan, New Zealand, Korea). In light of these findings, policymakers should consider and avoid energy design policies in the long term, especially in countries where shocks to oil consumption are temporary. In this case, policies aimed at reducing oil consumption, in the long run, will not be effective in countries where the oil consumption series is stationary. 


\section{Giriş}

Sanayi Devrimi ile birlikte üretimde makineleşmenin başlaması, sonrasında oluşan küreselleşme ve uluslararası ticaret artışı üretimin enerjiye daha çok bağımlı hale gelmesine neden olmuştur. Enerji kaynaklarının rezervlerinin sınırlı olması, eşit olmayan dağılımı ve artan enerji talepleri dikkatleri her zaman enerji üzerine yoğunlaştırmaktadır (Yalçın Erik \& Koşaroğlu, 2016). Petrol kaynaklarının yayılımı bölgeden bölgeye değişiklik gösterdiği için dünyada bazı ülkeler petrol için kaynak ülke, bazı ülkeler ise petrole bağımlı ülke konumundadır. Ekonomik faaliyetlerin büyük bir kısmı doğrudan veya dolaylı olarak enerjiye bağlı olduğundan ülkeler için petrolün ekonomik önemi tartışılmazdır.

2019 yılında ortaya çıkan Covid-19 pandemisi birçok sektörün yanında enerji sektörünü de etkilemiştir. 2020 yılında küresel enerji talebinin pandemi nedeniyle \%4.5 düştüğü tahmin edilmektedir. Bu durum II. Dünya Savaşı'ndan sonra yaşanan en büyük durgunluk anlamına gelmektedir. Dünya çapında petrol tüketimindeki düşüş, enerji talebindeki toplam düşüşün yaklaşık dörtte üçünü oluşturmaktadır. Petrol tüketimi günde 9.1 milyon varil (\% 9.3) azalarak 2011 yılından bu güne görülen en düşük seviyesine gerilemiştir. Petrol talebi en çok ABD (-2.3 milyon varil/gün), AB (-1.5 milyon varil/gün) ve Hindistan'da (-480.000 varil/ gün) düşmüştür. Çin ise tüketimin (220.000 varil/gün) arttı̆̆ı neredeyse tek ülkedir. Küresel petrol üretimi 6.6 milyon varil/gün küçülürken, Petrol İhraç Eden Ülkeler Örgütü (OPEC) ülkeleri bu düşüşün üçte ikisini oluşturmaktadır. Libya (-920.000 varil/gün) ve Suudi Arabistan (-790.000 varil/gün) OPEC ülkeleri arasında en büyük düşüşleri yaşarken, Rusya (-1.0 milyon varil/gün) ve ABD (-600.000 varil/gün) OPEC dışı düşüşlere öncülük etmiştir. Rafineri kullanımı 8.0 puan düşerek \%74.1'e gerilemiştir. Ayrıca 2020'de petrol fiyatı ortalama 41.84 \$/varildir. Bu değer 2004 yılından bu yana görülen en düşük değerdir (Bp Statistical Review of World Energy, 2021).

Petrol tüketimindeki bu değişimler göz önüne alındığında petrol tüketimine yönelik şokların etkisinin geçici mi yoksa kalıcı mı olduğunu belirlemek oldukça önemlidir. Petrol tüketim serisi durağan bulunursa, petrol tüketimine yönelik şokların geçici olduğu ve kısa dönemde eski durumuna döneceği anlamına gelmektedir. Eğer petrol tüketimi durağan değilse, bu durum petrol tüketimine yönelik şokların kalıcı olduğu anlamına gelmektedir (Apergis \& Payne, 2010; Solarin \& Lean, 2016). Enerji tüketiminin durağan olup olmadığ1, enerji tüketimini tahmin etmek için de gereklidir. Enerji tüketimine yönelik şokların kalıcı olması durumunda, enerjinin ekonomide yer alan diğer sektörler için önemi göz önüne alındığında, temel makroekonomik değişkenlerin bu kalıcılığı devralması beklenebilir. Durağan olmayan petrol tüketimi değişkeninin bu yapısı diğer değişkenlere aktarılarak birçok makroekonomik değişkenin durağanlık özellikleri değişebilmektedir. Bununla birlikte, enerji tüketimi durağan değilse, o zaman geçmiş davranışın gelecekteki talebi 
tahmin etmede hiçbir değeri yoktur. Yani durağan olmayan bir petrol tüketim serisi ile gelecekteki petrol talebini tahmin etmek mümkün olmayacaktır. Bu durumda geleceğe yönelik enerji talebi tahminlerini oluşturmak için enerji tüketimini açıklayan diğer değişkenlere bakmak gerekir (Lean \& Smyth, 2009). Enerji tüketiminin durağanlığının incelenmesi sürdürülebilir kalkınma hedefleri açısından da önemlidir. Çünkü birçok ülke karbon emisyonlarını azaltmak için yenilenebilir enerji yatırımlarını artırmaya ve fosil enerji kaynaklarına bağımlılı̆̆ı azaltmaya yönelik politikalar uygulamıştır. Ancak bu politikaların başarısı fosil enerji tüketiminin durağanlığına bağlıdır. Aslında çevre kalitesini iyileştirmeye yönelik politikalar ancak fosil enerji tüketiminin durağan olmadığı ve uygulanacak politika şoklarının kalıcı etkileri olduğu takdirde başarılı olacaktır. Öte yandan fosil enerji tüketimi durağan ise uygulanacak politika şokları kısa sürede etkisini kaybedecektir (Destek \& Sarkodie, 2020).

Perron (1989), birim kök analizi yapılırken yapısal kırılmaların dikkate alınmaması durumunda durağan bir serinin durağan dışı olarak belirlenmesinin olası olduğunu belirterek, böylesi bir durumda kurulan regresyon modeline ait çıkarım ve öngörülerin yanlış olabileceğini ifade etmiştir. Bu çalışma konu ile ilgili yapılan diğer çalışmalardan farklı olarak petrol tüketiminin durağanlığını hem keskin hem de yumuşak ve pürüzsüz kırılmaları dikkate alarak araştırmaktadır. Çalışmanın geri kalanı şu şekilde planlanmıştır. İkinci kısımda petrol fiyatlarının durağanlık özelliğini dikkate alan ampirik literatür incelenmiştir. Üçüncü kısımda ekonometrik yöntem ve ampirik bulgulara yer verilmiştir. Dördüncü kısımda sonuç ve politika önerileri ile çalışma sonlandırılmıştır.

\section{Literatür}

Literatür incelendiğinde enerji tüketimi serisinin durağanlık özelliklerini araştıran çalışmaların son yıllarda arttığı gözlemlenmektedir. Bu çalışmalardan Narayan ve Smyth (2007), 1979-2000 dönemi için 182 ülkenin enerji tüketimi serisinin durağanlık özelliklerini ADF ve Im, Pesaran ve Shin (2003) birim kök testlerini kullanarak incelemişlerdir. Çalışmada 56 ülke için enerji tüketimi serisinin durağan olduğu sonucuna ulaşılmıştır. Mishra, Sharma ve Smyth (2009), 1980-2005 dönemi için13 Pasifik ada ülkesinin enerji tüketimi serisinin durağanlığını Carrion-i-Silvestre, Barrio-Castro ve LópezBazo (2005) panel durağanlık testi kullanarak incelemişlerdir. Çalışmanın ekonometrik bulguları 8 ülke için enerji tüketimi serisinin durağan olduğunu göstermektedir. Ozcan ve Ozturk (2016), 32 OECD ülkesi ve 1971-2013 dönemini ele aldıkları çalışmalarında ekonometrik yöntem olarak Bahmani-Oskooee, Chang ve Wu (2014) panel durağanlık testini kullanmışlardır. Çalışmadan elde edilen sonuçlar 16 ülke için enerji tüketimi serisinin durağan olduğunu göstermektedir. Erdogan, Akalin ve Oypan (2020), 1970-2016 dönemi için Türkiye'de enerji tüketimi verilerinde şokların kalıcılığını Fourier panel KPSS testi 
kullanarak araştırmışlardır. Çalışmadan elde edilen sonuçlar enerji tüketiminin hem sektörel hem de panel düzeyinde durağan olmadığını göstermektedir. Bozoklu, Yilanci ve Gorus (2020), 1960-2014 dönemi ve 113 ülke için kişi başı toplam enerji tüketiminin durağanlığını kesirli Fourier birim kök testi kullanarak incelemişlerdir. Çalışmada, şokların kişi başına enerji tüketimi üzerinde sadece geçici etkileri olduğu ve uzun hafıza özelliği sayesinde yavaş yavaş ortadan kalkacağı sonucuna ulaşılmıştır.

Literatürde petrol tüketiminin durağanlığını konu edinen çok fazla çalışma olmadığı görülmektedir. Petrol tüketimini konu edinen çalışmalar incelendiğinde ele alınan ülke, dönem ve kullanılan ekonometrik analiz yöntemlerinin farklı olması sebebiyle ortak bir çıkarım yapmanın mümkün olmadığı görülmektedir. Bu çalışmalardan Lean ve Smyth, (2009), ABD için yaptıkları çalışmada 1973:01- 2008:07 aylık verileri kullanarak petrol tüketimini sektör bazında (konut, ticari, endüstriyel, ulaşım ve elektrik) incelemişlerdir. Analiz için tek değişkenli ve çok değişkenli kesirli LM birim kök testleri kullanılmıştır. Çok değişkenli test sonuçlarına göre, ticari ve endüstriyel sektörlerdeki petrol tüketiminin birim köklü, konut sektöründe ise petrol tüketiminin durağan olduğu sonucuna ulaşmışlardır.

Apergis ve Payne (2010), 1960-2007 dönemine ait verileri kullanarak ABD eyaletlerinde petrol tüketimi serisinin durağanlığını test etmiştir. Ekonometrik yöntem olarak yapısal kırılmaların içsel olarak belirlendiği Lee ve Strazicich (2003) ve Narayan ve Popp (2010) birim kök testleri kullanılmıştır. Çalışmada petrol tüketimi serisinin eyaletlerin çoğu için durağan olduğu sonucuna ulaşmışlardır.

Solarin ve Lean (2016), 1965-2012 dönemi verilerini kullanarak 57 ülke için petrol tüketiminin durağanlık özelliklerini incelemişlerdir. Çalışmada doğrusal ve doğrusal olmayan durağanlık testleri kullanılmıştır. Sonuç olarak 19 ülkede petrol tüketimi serisinin durağan olduğunu, 38 ülkede ise serilerin durağan olmadığını tespit etmişlerdir.

Destek ve Sarkodie (2020), 1970-2018 dönemine ait verileri kullanarak, 16 OECD ülkesi için kişi başı kömür, petrol ve doğal gaz tüketimi serilerinin durağanlık özelliklerini incelemişlerdir. Serilerin durağanlık özelliklerini belirlemek için Fourier ADF birim kök testi ve Fourier KSS birim kök testi kullanmışlardır. Çalışma sonucunda petrol, kömür ve doğalgaz tüketimine yönelik şokların çoğunun kalıcı olduğunu belirlemişlerdir.

Çağalayan-Akay, Ün ve Bülbül (2021), 1965-2018 dönemi için doğrusal, doğrusal olmayan ve Fourier temelli birim kök testini kullanarak Kırılgan Beşli Ülkeleri (Brezilya, Hindistan, Endonezya, Güney Afrika ve Türkiye) için birincil enerji tüketiminin durağan özelliklerini araştırmışlardır. Çalışmanın bulguları kömür tüketimindeki şokların etkisinin Brezilya, Güney Afrika ve Türkiye için geçici, Hindistan ve Endonezya için ise kalıcı olduğunu göstermektedir. Doğal gaz tüketimindeki şoklar ise sadece Güney Afrika için 
kalıcı bulunmuştur. Ayrıca petrol tüketiminde oluşacak şokların etkisi Hindistan ve Endonezya için geçici iken diğer ülkeler için kalıcıdır.

Ajlouni, Ghazo ve Abu-Lila (2021), Ürdün'de petrol ürünleri tüketiminin durağanlık özelliklerini 1961-2019 dönemine ait yıllık verileri kullanarak incelemişlerdir. Ekonometrik yöntem olarak ADF, PP, KPSS geleneksel birim kök testleri ile Lee ve Strazicich (2003) yapısal kırılmalı birim kök testini uygulamışlardır. Ampirik bulgular, petrol tüketimine yönelik şokların kalıcı bir etkiye sahip olduğunu göstermektedir.

Konu ile ilgili yapılan çalışmalar genel olarak değerlendirildiğinde genellikle ekonomik yapı, uluslararası kuruluşların yaptığı sınıflandırmalar ve farklı sektörler dikkate alınarak petrol tüketimi durağanlığının incelendiği görülmektedir. Bu çalışma mevcut literatüre iki açıdan katkıda bulunmaktadır. Birincisi, OECD ülkelerini ele alan tek çalışma olan Destek ve Sarkodie (2020)'den farklı olarak daha fazla ülke ele alınmaktadır. İkincisi, bu çalışma konu ile ilgili yapılan diğer çalışmalardan farklı olarak petrol tüketiminin durağanlığını hem keskin hem de yumuşak ve pürüzsüz kırılmaları dikkate alan panel durağanlık testi kullanarak araştırmaktadır. Hem keskin hem de yumuşak ve pürüzsüz kırılmaları dikkate alan panel durağanlık testinin kullanılması sonuçların güvenilirliği noktasında literatürde var olan farklı görüşleri değerlendirmek adına önemli olduğu düşünülmektedir. Dolayısıyla çalışmadan elde edilen sonuçların politika yapıcılara önemli bir rehber olmasının yanı sıra mevcut literatüre önemli bir katkı sağlaması amaçlanmaktadır.

\section{Veri Seti ve Yöntem}

Petrol tüketimine yönelik şokların etkisini incelemek için birim kök testleri kullanılabilmektedir. Birim kök testi literatürü yapısal değişimlerin dikkate alınmadı̆̆ Dickey ve Fuller (1979) birim kök testi ile başlamıştır. Sonra serinin seviyesinde veya trendinde yer alan yapısal değişiklikleri ele almak için yapay değişkenler kullanılmış ve keskin kırılmaların dikkate alındığı testler geliştirilmiştir. Daha sonra yapısal değişimlerin kademeli bir şekilde olabileceği düşüncesiyle doğrusal olmayan birim kök testleri geliştirilmiştir. Yapısal kırılmalar ile belirli doğrusal olmayan yapılar arasında ayrım yapmak oldukça güçtür. Bu nedenle yapısal kırılma ve kırılmalar içeren bir seri, parametrelerinde doğrusal olmayan bir sürecin özel bir hali olarak görülebilmektedir (Becker, Enders, ve Lee, 2006). Ekonomik zaman serisi verilerinin yapılarını yakalamada doğrusal olmayan modellerin oldukça faydalı olduğu kanıtlanmış olsa da, bu modellerde uygun fonksiyonel yapının seçilmesi önemli bir sorun olarak karşımıza çıkmaktadır. Ayrıca doğrusal olmayan modeller arasında kullanılacak en uygun modeli belirleyebilmek için olası seçenekler de oldukça fazladır. Üstel Yumuşak Geçişli Otoregresif Süreç (ESTAR) Modeli, Lojistik Yumuşak Geçişli Otoregresif Süreç (LSTAR) Modeli, Markov Değişim Modeli gibi birçok 
alternatif doğrusal olmayan model arasından seçim yapılabilmektedir. Fakat bu modeller kullanılırken fonksiyonel formun yanlış tanımlanması, doğrusal olmama durumunu tamamen göz ardı etmek kadar problemli olabilmektedir. Bu çalışmada söz konusu problemlerin üstesinden gelebilmek amacıyla Fourier yaklaşımı kullanılmıştır. Bu yaklaşım, ele alınan modelin deterministik bileşeninde bilinmeyen formda ve sayıda yapısal kırılmayı veya ihmal edilen doğrusal olmama durumunu yakalayabilmek amaciyla kullanılabilmektedir. Fourier yaklaşımının kullanılması ile birlikte, uygun fonksiyonel formun seçilmesi sorunu, yaklaşıma dâhil edilecek uygun frekans sayısını seçmeye dönüşmektedir (Jones \& Enders, 2014).

Bu çalışmada OECD (Ekonomik Kalkınma ve İşbirliği Örgütü)'ye üye 33 ülke (Kanada, Meksika, ABD, Şili, Kolombiya, Avusturya, Belçika, Çekya, Danimarka, Finlandiya, Fransa, Almanya, Yunanistan, Macaristan, İzlanda, İrlanda, İtalya, Lüksemburg, Hollanda, Norveç, Polonya, Portekiz, Slovakya, İspanya, İsveç, İsviçre, Türkiye, Birleşik Krallık, İsrail, Avustralya, Japonya, Yeni Zelanda, Kore) ele alınmıştır. Bu doğrultuda 1965-2019 yıllarına ait petrol tüketimi serilerinin durağanlığı hem keskin hem de yumuşak ve pürüzsüz kırılmaları göz önünde bulunduran panel durağanlık testi kullanılarak araştırılmıştır. Bu test prosedüründe keskin kırılmaları ve yumuşak kırılmaları yakalayabilmek için sırasıyla kırılma tarihlerinin içsel olarak belirlendiği kukla değişkenler ve Fourier yaklaşımı kullanılmıştır. Petrol tüketimi (Milyon Ton) verilerine BP Statistical Review of World Energy (Haziran 2020) veri tabanından ulaşılmıştır.

\subsection{Yatay Kesit Bağımlılığı}

Durağanlık testini uygulamadan önce panel üyeleri arasında yatay kesit bağımlılığının varlığı araştırılmalıdır. Pesaran (2006), birimler arasında yatay kesit bağımlılı̆̆ının olması durumunda, bu durumun dikkate alınmamasının yanlılık ve boyut bozulmaları sorunlarına neden olabileceğini ifade etmiştir (Hsueh, Hu, ve Tu, 2013). Bu nedenle ekonometrik analizlerde ilk olarak ülkeler arasında yatay kesit bağımlılığının olup olmadığı incelenmiştir. Yatay kesit bağımlılı̆̆ı test edilirken yatay kesit boyutunun zaman boyutundan küçük olduğu durumlar için Breusch ve Pagan (1980) tarafından geliştirilen LM testi kullanılabilmektedir. $L M$ test istatistiğini elde edebilmek için Denklem (1) kullanılmaktadır:

$$
L M=T \sum_{i=1}^{N-1} \sum_{j=i+1}^{N} \hat{\rho}_{i j}^{2}
$$

Pesaran, Ullah ve Yamagata (2008) çalışmalarında $L M$ testinin kesin ortalamasını ve varyansını kullanmış ve $L M$ testinin sapması düzeltilmiş bir versiyonu olan $L M_{\text {adj }}$ testini geliştirmişlerdir. $L M_{a d j}$ test istatistiğini elde etmek için ise Denklem (2) kullanılmaktadır: 


$$
L M_{a d j}=\left(\frac{2}{N(N-1)}\right)^{1 / 2}\left(\sum_{i=1}^{N-1} \sum_{j=i+1}^{N} \hat{\rho}_{i j} \frac{(T-k) \hat{\rho}_{i j}^{2}-\mu_{T i j}}{v_{T i j}}\right)
$$

Burada, $k$ değeri regresörlerin sayısını, $\mu_{T i j}$ ve $v_{T i j}$ ise sırasıyla ortalama ve varyansı temsil etmektedir. Yatay kesit bağımlılığı testlerinin boş hipotezleri yatay kesit bağımlılığının olmadığını ifade etmektedir.

\subsection{Li, Ranjbar ve Chang (2015) Panel Durağanlık Testi}

Li, Ranjbar ve Chang (LRC, 2015) panel durağanlık testi, Carrion-i Silvestre, BarrioCastro ve Lopez-Bazo (CBL, 2005) tarafından önerilen durağanlık testini temel almaktadır. LRC testinde, veri yapısında bulunan hem keskin hemde yumuşak yapısal kırılmalar göz önünde bulundurulmaktadır. CBL testinde, durağanlık boş hipotezi altında oluşturulan veri yaratma süreci aşağıdaki modele dayanmaktadır:

$$
y_{i t}=\alpha+\beta t+\sum_{k=1}^{m} \theta_{i k} D U_{k, t}+\sum_{k=1}^{m} \rho_{i k} D T_{k, t}+\varepsilon_{i t}
$$

Denklem (3)'de $\alpha$ sabit terimi, $t$ trend terimini, $m$ ise uygun kırılma sayısını ifade etmektedir. CBL testinde test istatistiği Denklem (4) kullanılarak hesaplanmaktadır:

$$
Z(\lambda)=\frac{\left(\sum_{i=1}^{N} L M\left(\lambda_{i}\right)-N \bar{\mu}_{L M}\right)^{0.5}}{\sigma_{L M}} \rightarrow^{d} N(0,1)
$$

Burada $L M\left(\lambda_{i}\right)$, Kwiatkowski, Phillips, Schmidt ve Shin (KPSS, 1992) tarafindan önerilen test istatistiğini göstermektedir. $\bar{\mu}_{L M}$ ve $\sigma_{L M}$ ise sırasıyla $L M\left(\lambda_{i}\right)$ dağılımının ortalaması ve standart sapmasıdır. LRC testinde, yumuşak ve pürüzsüz kırılmaları modele dâhil etmek amacıyla Fourier yapı kullanılmaktadır:

$$
y_{t}=\alpha+\beta t+\sum_{i=1}^{m+1} \theta_{i} D U_{i, t}+\sum_{i=1}^{m+1} \rho_{i} D T_{i, t}+\sum_{k=1}^{n} \gamma_{1, k} \sin \left(\frac{2 \pi k t}{T}\right)+\sum_{k=1}^{n} \gamma_{2, k} \cos \left(\frac{2 \pi k t}{T}\right)+\varepsilon_{t}
$$

Denklem (5)'de yer alan $k$ frekans sayısını, $T$ ise örneklem büyüklüğünü göstermektedir. Burada keskin kırılmaları modele dâhil etmek için kullanılan $D U$ ve $D T$ kukla değişkenleri Denklem (6) ve Denklem (7)'de verildiği gibi tanımlanmaktadır:

$$
\begin{aligned}
& D U_{k, t}=\left\{\begin{array}{cc}
1 & \text { Ĕ } \mathrm{g} e r ~ T B_{k-1}<t<T B_{k} \text { ise } \\
0 & \text { diğer durumlarda }
\end{array}\right. \\
& D T_{k, t}=\left\{\begin{array}{cc}
t-T B_{k-1} & \text { Ĕ } \text { er } T B_{k-1}<t<T B_{k} \text { ise } \\
0 & \text { diğer durumlarda }
\end{array}\right.
\end{aligned}
$$


Enders ve Lee (2012) çalışmalarında serbestlik derecesini azaltmak ve aşırı uyum problemini önlemek için $n=1$ alınmasının uygun olacağını ifade etmişlerdir. Bu nedenle $n=1$ kısıtı altında Denklem (5) yeniden yazılabilmektedir:

$$
y_{t}=\alpha+\beta t+\sum_{i=1}^{m+1} \theta_{i} D U_{i, t}+\sum_{i=1}^{m+1} \rho_{i} D T_{i, t}+\gamma_{1} \sin \left(\frac{2 \pi k t}{T}\right)+\gamma_{2} \cos \left(\frac{2 \pi k t}{T}\right)+\varepsilon_{t}
$$

Li, Ranjbar ve Chang (2015), Denklem (8)'i tahmin etmek için iki aşamalı bir prosedür önermişlerdir. Birinci aşamada uygun kırılma sayısı olan $m$ ve uygun frekans sayısı olan $k^{*}$ değerleri belirlenmektedir. Li, Ranjbar ve Chang (2015), çalışmalarında k'nın maksimum değerini 7 olarak ele almışlardır. Öncelikle 1'den 7'ye kadar olan frekans değerleri için Bai ve Perron (1998) tarafindan geliştirilen yöntem kullanarak Denklem (8) tahmin edilmektedir. Kalıntı kareler toplamının minimum olduğu frekans değeri uygun frekans değeri $\left(k^{*}\right)$ değeri olarak belirlenmektedir. Daha sonra $k^{*}$ frekans değeri kullanılarak Denklem (8) yeniden tahmin edilerek, uygun kırılma sayısı ve konumu belirlenmektedir.

İkinci aşamada Denklem (8) kullanılarak doğrusal olmayan yapının olmadığı yani trigonometrik terimlerin anlamlı olup olmadığı test edilmektedir. Bu doğrultuda Becker, Enders ve Lee (2006) takip edilerek Denklem (9) ile verilen $F$ istatistiği kullanılmaktadır:

$$
F\left(k^{*}\right)=\frac{\left(S S R_{0}-S S R_{1}\left(k^{*}\right)\right) / 2}{S S R_{1}\left(k^{*}\right) /(T-q)}
$$

Burada $S S R_{1}\left(k^{*}\right)$, Denklem (8) kullanılarak elde edilen kalıntı kareler toplamını, $S S R_{0}$, trigonometrik terimler olmadan elde edilen kalıntı kareler toplamını, $q$ değeri ise regresörlerin sayısını göstermektedir.

\subsection{Bulgular}

Çalışmada kullanılan değişkenlere ait durağanlık sınamaları yapılmadan önce birimler arasında yatay kesit bağımlılı̆̆ının olup olmadığı LM (Breusch ve Pagan, 1980), Pesaran CDLM (Pesaran, 2004), Pesaran CD (Pesaran, 2004) ve $L M_{a d j}$ (Pesaran, Ullah ve Yamagata, 2008) testleri kullanılarak araştırılmıştır. Petrol tüketimi serilerine ait yatay kesit bağımlılığı sonuçları Tablo 1'de sunulmuştur.

Tablo 1: Yatay Kesit Bağımlılı̆ğ Testi Sonuçları

\begin{tabular}{lcc}
\hline Yöntem & Test İstatistiği & p-değeri \\
\hline $\boldsymbol{L M}$ & 2414,38 & 0,000 \\
Pesaran $\boldsymbol{C D} \boldsymbol{L} \boldsymbol{M}$ & 17,054 & 0,000 \\
Pesaran $\boldsymbol{C D}$ & $-1,292$ & 0,098 \\
$\boldsymbol{L M}_{\text {adj }}$ & 25,30 & 0,000 \\
\hline
\end{tabular}


$L M$, Pesaran $C D L M$ ve $L M_{a d j}$ testi sonuçları incelendiğinde, elde edilen olasıllı değerleri 0.05 değerinden küçük olduğu için yatay kesit bağımlılığının olmadığı ifade eden boş hipotez reddedilmektedir. Diğer bir ifadeyle yatay kesit bağımlılığı sonuçları birimler arasında yatay kesit bağımlılı̆̆ının olduğunu göstermektedir. Bu sonuçlara göre OECD ülkelerinin birinde meydana gelen herhangi bir şok diğer OECD ülkelerini de etkilemektedir. Bu sonuçlar ile birlikte durağanlık sınamaları yapılırken yatay kesit bağımlılığını göz önünde bulunduran testlerin kullanılması gerekmektedir. Bu doğrultuda ele alınan serilerin durağanlık özellikleri yatay kesit bağımlılığını dikkate alan ve Li, Ranjbar ve Chang (2015) tarafından geliştirilen durağanlık testi kullanılarak araştırılmaktadır. Krılmalı Fourier panel durağanlık testi sonuçları Tablo 2'de verilmiştir.

Tablo 2: Kırılmalı Fourier Panel Durağanlık Testi Sonuçları

\begin{tabular}{|c|c|c|c|c|c|}
\hline \multicolumn{6}{|c|}{ Panel A: Panel Durağanlık Testi Sonuçları } \\
\hline & & & Test İstatistiği & $\begin{array}{l}\text { Kritik Değer } \\
(\% 5)\end{array}$ & p-değeri \\
\hline \multicolumn{3}{|c|}{ Homojen Panel KPSS İstatistiği } & $-6,371$ & 8,868 & 0,999 \\
\hline \multicolumn{3}{|c|}{ Heterojen Panel KPSS İstatistiği } & $-5,181$ & $-1,765$ & 0,999 \\
\hline \multicolumn{6}{|c|}{ Panel B: Birimlerin Durağanlık Testi Sonuçları } \\
\hline Ülkeler & Barlett & $\begin{array}{c}\text { Kritik Değer } \\
(\% 5)\end{array}$ & Ülkeler & Barlett & $\begin{array}{c}\text { Kritik Değer } \\
(\% 5)\end{array}$ \\
\hline Kanada & $0,054^{*}$ & 0,109 & Lüksemburg & $0,073 *$ & 0,088 \\
\hline Meksika & 0,114 & 0,065 & Hollanda & $0,093 *$ & 0,145 \\
\hline ABD & $0,054 *$ & 0,138 & Norveç & $0,057 *$ & 0,158 \\
\hline Şili & 0,079 & 0,054 & Polonya & 0,110 & 0,053 \\
\hline Kolombiya & $0,060 *$ & 0,124 & Portekiz & $0,052 *$ & 0,078 \\
\hline Avusturya & $0,130 *$ & 0,131 & Slovakya & $0,062 *$ & 0,097 \\
\hline Belçika & $0,066 *$ & 0,101 & İspanya & $0,091 *$ & 0,106 \\
\hline Çekya & $0,057 *$ & 0,097 & İsveç & $0,040^{*}$ & 0,165 \\
\hline Danimarka & $0,050 *$ & 0,076 & İsviçre & $0,066^{*}$ & 0,244 \\
\hline Finlandiya & $0,077 *$ & 0,108 & Türkiye & 0,144 & 0,074 \\
\hline Fransa & $0,038^{*}$ & 0,105 & Birleşik Krallık & $0,028^{*}$ & 0,100 \\
\hline Almanya & $0,050 *$ & 0,120 & İsrail & 0,089 & 0,088 \\
\hline Yunanistan & $0,033 *$ & 0,146 & Avustralya & 0,119 & 0,118 \\
\hline Macaristan & $0,045^{*}$ & 0,099 & Japonya & 0,147 & 0,080 \\
\hline İzlanda & 0,215 & 0,211 & Yeni Zelanda & 0,148 & 0,108 \\
\hline İrlanda & $0,034 *$ & 0,093 & Kore & 0,145 & 0,129 \\
\hline İtalya & $0,109 *$ & 0,265 & & & \\
\hline
\end{tabular}

Not: *, \% 5 düzeyinde durağanlı̆̆ı ifade etmektedir. 
Tablo 2'de Panel A panelin geneli için, Panel B ise ülkelere ait durağanlık testi sonuçlarını göstermektedir. Bu sonuçlar incelendiğinde panelin geneli için olasılık değerleri 0.05 'den büyük olarak bulunmuştur. Bundan dolayı panelin genelinin durağan olduğunu ifade eden boş hipotez reddedilememiştir ve panel durağan bulunmuştur. Diğer taraftan bireysel durağanlık testi sonuçları 23 ülke (Kanada, ABD, Kolombiya, Avusturya, Belçika, Çekya, Danimarka, Finlandiya, Fransa, Almanya, Yunanistan, Macaristan, İrlanda, İtalya, Lüksemburg, Hollanda, Norveç, Portekiz, Slovakya, İspanya, İsveç, İsviçre, Birleşik Krallık) için petrol tüketimi serisinin durağan olduğunu ortaya koymaktadır. Yine bireysel durağanlık testi sonuçlarına göre 10 ülke için ise (Meksika, Şili, İzlanda, Polonya, Türkiye, İsrail, Avustralya, Japonya, Yeni Zelanda, Kore) boş hipotez reddedilmektedir. Yani söz konusu 10 ülke için petrol tüketimi serisi birim köklü bulunmuştur.

Tablo 3: Uygun Frekans Değerleri ve F-istatistikleri

\begin{tabular}{lccccccc}
\hline Ülkeler & $\mathbf{k}^{*}$ & F-İstatistiği & $\begin{array}{c}\text { Kritik } \\
\text { Değer (\%5) }\end{array}$ & Ülkeler & $\mathbf{k}^{*}$ & F-i̇statistiği & $\begin{array}{c}\text { Kritik } \\
\text { Değer (\%5) }\end{array}$ \\
\hline Kanada & 2 & 115,33 & 3,165 & Lüksemburg & 2 & 54,28 & 3,157 \\
Meksika & 1 & 140,44 & 3,138 & Hollanda & 2 & 58,70 & 3,067 \\
ABD & 2 & 44,30 & 3,108 & Norveç & 2 & 22,12 & 3,105 \\
Şili & 1 & 15,19 & 3,189 & Polonya & 1 & 49,20 & 3,087 \\
Kolombiya & 3 & 65,54 & 3,184 & Portekiz & 1 & 234,89 & 3,121 \\
Avusturya & 2 & 17,51 & 3,117 & Slovakya & 2 & 2,75 & 3,097 \\
Belçika & 2 & 85,10 & 3,209 & İspanya & 2 & 123,96 & 3,150 \\
Çekya & 2 & 17,00 & 3,084 & İsveç & 1 & 35,92 & 3,065 \\
Danimarka & 1 & 12,21 & 3,142 & İsviçre & 3 & 12,86 & 3,234 \\
Finlandiya & 2 & 33,57 & 3,118 & Türkiye & 1 & 133,35 & 3,209 \\
Fransa & 2 & 100,66 & 3,104 & Birleşik & 2 & 48,40 & 3,127 \\
Almanya & 2 & 43,81 & 3,110 & İ́srail & 2 & 9,82 & 3,112 \\
Yunanistan & 2 & 110,77 & 3,131 & Avustralya & 2 & 48,82 & 3,155 \\
Macaristan & 1 & 121,54 & 3,123 & Japonya & 1 & 60,38 & 3,151 \\
İzlanda & 4 & 15,66 & 3,190 & Yeni Zelanda & 1 & 44,18 & 3,173 \\
İlanda & 2 & 140,76 & 3,146 & Kore & 2 & 9,90 & 3,174 \\
İtalya & 3 & 7,77 & 3,250 & & & & \\
\hline
\end{tabular}


Tablo 3'de Fourier fonksiyonuna ait her bir ülke için belirlenen uygun frekans sayıları, Fourier terimlerin anlamlılığını test etmek için F-istatistikleri ve kritik değerler yer almaktadır. Tablo 3 incelendiğinde Slovakya haricinde tüm ülkeler için hesaplanan $F$-istatistikleri kritik değerlerden büyük olduğu için Fourier terimlerin anlamlı olduğu görülmektedir. Bu sonuç Fourier yaklaşımın, çalışmada kullanılan verilerin durağanlığını sınamada uygun bir yaklaşım olduğunu göstermektedir. Her bir OECD ülkesi için tahmin edilen kırılma tarihleri Tablo 4'de yer almaktadır. Çalışmada kullanılan gözlem sayısı göz önünde alındığında maksimum kırılma sayısının 2 olarak belirlenmesine karar verilmiştir. Macaristan, Hollanda ve İsveç için uygun kırılma sayısı 1 olarak, diğer ülkeler için 2 olarak elde edilmiştir. Genel olarak, kırılma tarihlerinin yaklaşık \%14'ü 1970'lerin sonundaki küresel petrol krizinin etkisiyle 1970'lerin sonlarında ve 1980'lerin başlarında; yine yaklaşık \%14'ü 1986 yılındaki petrol krizinin etkisiyle 1980'lerin sonlarında yer almaktadır. Yapısal kırılmaların yaklaşık \%16'sı ise Körfez Savaşı'nın etkisiyle 1990'ların başında gerçekleşmiştir. Grafik 1'de ülkelere ait seriler ve yapısal değişimler verilmiştir. Keskin kırılmaları, yumuşak ve pürüzsüz kırılmaları ele alan yaklaşımın genel itibariyle serilere uyumunun oldukça iyi olduğu görülmektedir.

Tablo 4: Ülkeler için Tahmin Edilen Kırılma Tarihleri

\begin{tabular}{lccccc}
\hline Ülkeler & Karılma 1 & Kırılma 2 & Ülkeler & Karılma 1 & Kurılma 2 \\
\hline Kanada & 1987 & 2010 & Lüksemburg & 1986 & 2003 \\
Meksika & 1971 & 1978 & Hollanda & 1987 & - \\
ABD & 1971 & 1986 & Norveç & 1969 & 1985 \\
Şili & 1993 & 2006 & Polonya & 1996 & 2005 \\
Kolombiya & 1983 & 2003 & Portekiz & 1991 & 1997 \\
Avusturya & 1970 & 2000 & Slovakya & 1971 & 1990 \\
Belçika & 1977 & 2005 & İspanya & 1979 & 1988 \\
Çekya & 1971 & 1989 & İsveç & 1982 & - \\
Danimarka & 1969 & 1979 & İsviçre & 1969 & 2006 \\
Finlandiya & 1969 & 1994 & Türkiye & 1972 & 2014 \\
Fransa & 1969 & 1993 & Birleșik Krallık & 1994 & 2004 \\
Almanya & 1969 & 1998 & İsrail & 1978 & 1993 \\
Yunanistan & 1978 & 1986 & Avustralya & 1986 & 2011 \\
Macaristan & 1973 & - & Japonya & 1969 & 1980 \\
İzlanda & 1992 & 2014 & Yeni Zelanda & 1970 & 1993 \\
İrlanda & 1985 & 2004 & Kore & 1989 & 1994 \\
İtalya & 1969 & 2008 & & & \\
\hline
\end{tabular}




\section{Tartışma ve Sonuç}

Petrole bağımlılı̆̆ı azaltmak için uygulanacak politikaların başarısı, petrol tüketim serilerinin durağan olup olmamasına bağlıdır. Bu çalışmada Fourier panel durağanlık testi kullanılarak OECD ülkeleri için petrol tüketimi serisinin durağanlığ Literatürde yer alan çalışmaların çoğunda ekonometrik yöntem olarak ya keskin kırılmalı ya da yumuşak ve pürüzsüz kırılmalı zaman serisi yöntemlerinin kullanıldığg görülmektedir. Bu çalışmada literatürdeki çalışmalardan farklı olarak her iki kırılma yapısını dikkate alan panel durağanlık testi kullanılmıştır. OECD ülkelerine ait petrol tüketimi serileri ve yapısal değişimler incelendiğinde hem keskin kırılmaları hem de yumuşak ve pürüzsüz kırılmaları birlikte ele alan yaklaşımın oldukça iyi olduğu görülmektedir.

Çalışmadan elde edilen ekonometrik bulgular panelin geneli için petrol tüketimi serisinin durağan olduğunu göstermektedir. Bireysel durağanlık sonuçlarına göre 23 ülke (Kanada, ABD, Kolombiya, Avusturya, Belçika, Çekya, Danimarka, Finlandiya, Fransa, Almanya, Yunanistan, Macaristan, İrlanda, İtalya, Lüksemburg, Hollanda, Norveç, Portekiz, Slovakya, İspanya, İsveç, İsviçre, Birleşik Krallık) için petrol tüketimi serisi durağan olarak elde edilmiştir. 10 ülke için ise (Meksika, Şili, İzlanda, Polonya, Türkiye, İsrail, Avustralya, Japonya, Yeni Zelanda, Kore) petrol tüketimi serisi birim köklüdür. Çalışmadan elde edilen sonuçlara göre, OECD ülkelerinde sürdürülebilir kalkınma hedefleri için uygulanacak politikaların her ülke üzerinde farklı etkileri olabileceğini söylemek mümkündür. Dolayısıyla petrol tüketimi serisi durağan olan ülkelerde politika şokunun geçici, durağan olmayan ülkelerde için ise kalıcı olacağı ifade edilebilir. 
Grafik 1. Ülkelere Ait Seriler ve Yapısal Değişimler

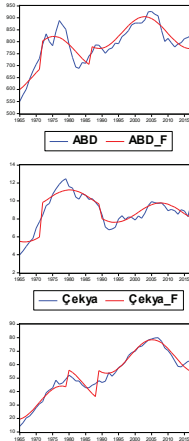

- ispanya - Ispanya_F

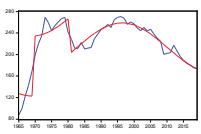

- Japonya - Japonya_F
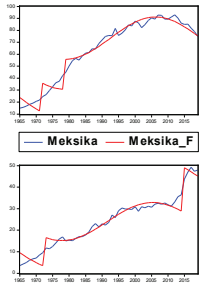

- Türkiye - Türkiye_F
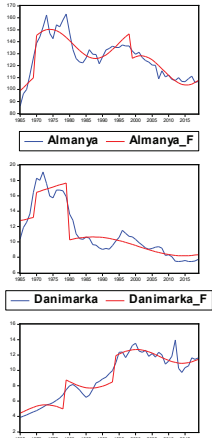

- Israil — Israil_F
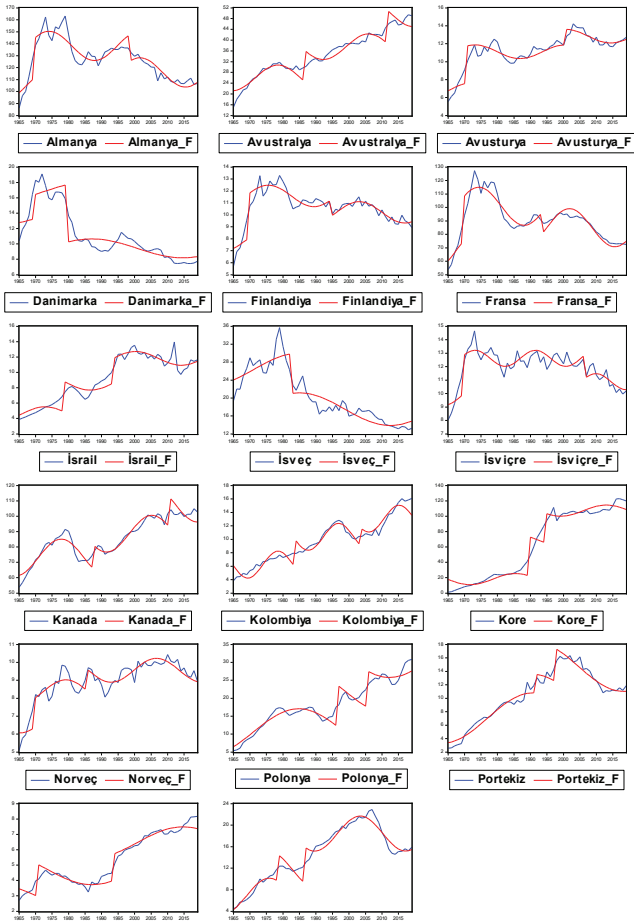

- Isviçre - Isviçre_f
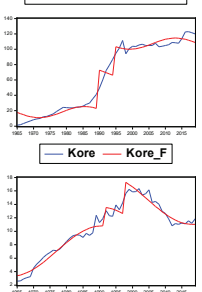

- Portekiz - Portekiz_F
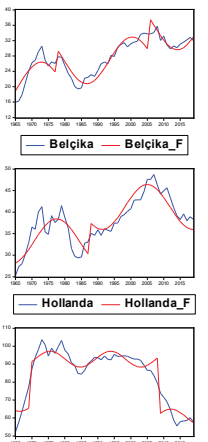

- italya - italya_F

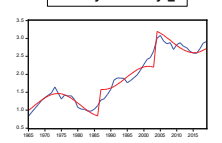

- Izlanda - Izlanda_F

Literatürde konu ile ilgili çalışmalarda yapılan ekonometrik analizlerde daha çok birim kök lehine sonuçlar elde edilmiştir. Bu çalışmada ise literatürde yer alan çalışmalardan farklı olarak daha çok durağanlık lehine sonuçlar elde edilmiştir. Çalışmadan elde edilen bulgular, Destek ve Sarkodie (2020)'nin Canada, Almanya, ABD, Şili, Polonya ve Japonya için elde ettikleri bulgularla, Çağalayan-Akay, Ün ve Bülbül (2021)'ün Türkiye için elde ettikleri bulgularla benzerlik göstermektedir. Çalışmanın sonuçları önemli politika çıkarımlarına sahiptir. İlk olarak özellikle petrol tüketimine yönelik şokların geçici olduğu 23 ülkede, politika yapıcıların bu bulguyu dikkate alması ve uzun dönemde enerji tasarımı politikalarından kaçınması gerekmektedir. Bu durumda uzun dönemde petrol tüketimini azaltmayı amaçlayan enerji talep yönetimi politikaları, petrol tüketim serisinin durağan olduğu ülkelerde etkili olmayacaktır. Çünkü bu politikaların tetiklediği yeniliklerin petrol tüketimi üzerinde uzun süreli bir etkisi olmayacaktır. Ayrıca petrol talebindeki aksamaların ekonomik aktivite üzerinde yalnızca geçici bir etkisi olacaktır. İkinci olarak petrol tüketimi serisinin durağan olduğu yani petrol tüketine yönelik şokların geçici olduğu ülkelerde geçmiş değerler kullanılarak petrol tüketiminin gelecekteki değerleri tahmin edilebilmektedir. $\mathrm{Bu}$ durum enerji politikasının oluşturulmasında yardımcı olabilmektedir. 
Petrol tüketiminden kaynaklı sera gazı emisyonları iklim değişikliğine etki etmektedir. 2020 yılında petrol tüketimi \%9.3 azalarak 2011'den bu yana en düşük seviyesine gerilemiş, yenilenebilir enerji ise 10 yıllık ortalamasının (yıllık \%13.4) altında kalmasına rağmen \%9.7 oranında artmıştır. Covid-19 krizinden çıkarken, ülkelerin daha sürdürülebilir kalkınma hedefleri için kararlı değişiklikler yapması gerekmektedir. Aynı zamanda petrole olan bağımlılık azaltılarak enerji kaynaklarının daha verimli kullanımı sağlanmalıdır. Ayrıca yenilenebilir enerjiler, elektrifikasyon, hidrojen, CCS (karbon yakalama ve depolama), biyoenerji gibi sıfır veya düşük karbonlu enerji teknolojilerin kullanımı arttırılmalıdır.

Hakem Değerlendirmesi: Dış bağımsız.

Çıkar Çatışması: Yazarlar çıkar çatışması beyan etmemişlerdir.

Finansal Destek: Yazarlar finansal destek beyan etmemişlerdir.

Peer-review: Externally peer-reviewed.

Conflict of Interest: The author has no conflict of interest to declare.

Grant Support: Authors declared no financial support.

\section{Kaynakça/References}

Ajlouni, S. A., Ghazo, A. M., \& Abu-Lila, Z. M. (2021). Are shocks to petroleum products consumption permanent or temporary: A new evidence from LM unit root tests with structural breaks. Emerging Science Journal, 5(3), 322329.

Apergis, N. \& Payne, J.E. (2010). Structural breaks and petroleum consumption in US states: Are shock transitory or permanent?. Energy Policy, 38(10), 6375-6378.

Bahmani-Oskooee, M., Chang, T., \& Wu, T. (2014). Revisiting purchasing power parity in African countries: panel stationary test with sharp and smooth breaks. Applied Financial Economics, 24(22), 1429-1438.

Bai, J. \& Perron, P. (1998). Estimating and testing linear models with multiple structural changes. Econometrica, 66, 47-78.

Becker, R., Enders, W., \& Lee, J. (2006) . A stationarity test in the presence of an unknown number of smooth breaks. Journal of Time Series Analysis, 27(3), 381-409.

Bozoklu, S., Yilanci, V., \& Gorus, M. S. (2020). Persistence in per capita energy consumption: a fractional integration approach with a Fourier function. Energy Economics, 91, 104926.

Bp (2020). Statistical Review of World Energy 2020 | 69th edition. https://www.bp.com/content/dam/bp/businesssites/en/global/corporate/pdfs/energy-economics/statistical-review/bp-stats-review-2020-full-report.pdf

Bp (2021). Statistical Review of World Energy 2021 | 70th edition. https://www.bp.com/content/dam/bp/businesssites/en/global/corporate/pdfs/energy-economics/statistical-review/bp-stats-review-2021-full-report.pdf

Breusch, T. S. \& Pagan, A. R. (1980). The lagrange multiplier test and its applications to model specification in econometrics. The Review of Economic Studies, 47(1), 239-253.

Carrion-i-Silvestre, J., L., Barrio-Castro, D., \& López-Bazo, E. (2005). Breaking the panels: An application to the gdp per capita. The Econometrics Journal, 8(2), 159-175.

Çağalayan-Akay, E., Ün, T., \& Bülbül, H. (2021). Investigating the stationary properties of coal, natural gas, and oil consumption: The case of fragile five countries. Doğuş Üniversitesi Dergisi, 22(1), 75-86.

Destek, M. A., \& Sarkodie, S. A. (2020). Are fluctuations in coal, oil and natural gas consumption permanent or transitory? Evidence from OECD countries. Heliyon, 6(2), e03391, 1-6. 
Dickey, D. A., \& Fuller, W. A. (1979). Distribution of the estimators for autoregressive time series with a unit root. Journal of the American Statistical Association, 74(366a), 427-431.

Dickey, D. A., \& Fuller, W. A. (1981). Likelihood ratio statistics for autoregressive time series with a unit root. Econometrica: Journal of the Econometric Society, 49, 1057-1072.

Enders, W. \& Lee, J. (2012). A unit root test using a Fourier series to approximate smooth breaks. Oxford Bulletin of Economics and Statistics, 74(4), 574-599.

Erdogan, S., Akalin, G., \& Oypan, O. (2020). Are shocks to disaggregated energy consumption transitory or permanent in Turkey? New evidence from fourier panel KPSS test. Energy, 197, 117174.

Hsueh, S. J., Hu, Y. H. \& Tu, C. H. (2013). Economic growth and financial development in Asian countries: A bootstrap panel Granger causality analysis. Economic Modelling, 32, 294-301.

Im, K. S., Pesaran, M. H., \& Shin, Y. (2003). Testing for unit roots in heterogeneous panels. Journal of Econometrics, $115(1), 53-74$

Jones, P. M., \& Enders, W. (2014). On the use of the flexible Fourier form in unit root tests, endogenous breaks, and parameter instability. In Recent Advances in Estimating Nonlinear Models, 59-83.

Kwiatkowski, D., Phillips, P. C., Schmidt, P., \& Shin, Y. (1992). Testing the null hypothesis of stationarity against the alternative of a unit root: how sure are we that economic time series have a unit root?. Journal of Econometrics, 54(1-3), 159-178.

Lean, H.H. \& Smyth, R. (2009). Long memory in US disaggregated petroleum consumption: evidence from univariate and multivariate LM tests for fractional integration. Energy Policy 37(8), 3205-3211.

Lee, J., \& Strazicich, M. C. (2003). Minimum lagrange multiplier unit root test with two structural breaks. The Review of Economics and Statistics, 85(4), 1082-1089.

Li, J. P., Ranjbar, O., \& Chang, T. (2015). Unemployment hysteresis in PIIGS countries: A new test with both sharp and smooth breaks. The Singapore Economic Review, 60(4) 1-13.

Mishra, V., Sharma, S., \& Smyth, R. (2009). Are fluctuations in energy consumption per capita transitory? Evidence from a panel of Pacific Island countries. Energy Policy, 37(6), 2318-2326.

Narayan, P. K., \& Smyth, R. (2007). Are shocks to energy consumption permanent or temporary? Evidence from 182 countries. Energy Policy, 35(1), 333-341.

Narayan, P. K., \& Popp, S. (2010). A new unit root test with two structural breaks in level and slope at unknown time. Journal of Applied Statistics, 37(9), 1425-1438.

Ozcan, B., \& Ozturk, I. (2016). A new approach to energy consumption per capita stationarity: Evidence from OECD countries. Renewable and Sustainable Energy Reviews, 65, 332-344.

Perron, P. (1989). The great crash, the oil price shock, and the unit root hypothesis. Econometrica: Journal of the Econometric Society, 57(6), 1361-1401.

Pesaran, M. H. (2004). General diagnostic tests for cross section dependence in panels. CESifo Working Paper 1229. IZA Discussion Paper, 1240.

Pesaran, M. H. (2006). Estimation and inference in large heterogeneous panels with a multifactor error structure. Econometrica, 74(4), 967-1012.

Pesaran, M., H., Ullah, A. \& Yamagata, T. (2008). A bias-adjusted LM test of error cross-section İndependence. Econometrics Journal, 11, 105-127.

Solarin, S. A., \& Lean, H. H. (2016). Are fluctuations in oil consumption permanent or transitory? Evidence from linear and nonlinear unit root tests. Energy Policy, 88, 262-270.

Yalçın Erik, N., \& Koşaroğlu, Ş. M. (2016). Tarihsel süreç boyunca değişen petrol fiyatları; Şeyl gazı etkisi ve bazı öngörüler. Cumhuriyet Üniversitesi İktisadi ve İdari Bilimler Dergisi, 17(2), 119-143. 
